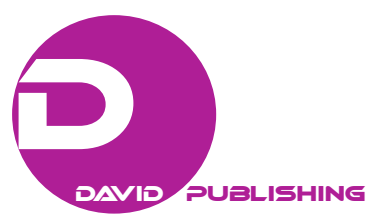

\title{
On the Legislative Process of the Right to Be Forgotten*
}

\author{
XIAO Peng \\ School of Foreign Studies, Zhongnan University of Economics and Law, Wuhan, China \\ LIN Haoran \\ Law School, Sun Yat-Sen University, Guangzhou, China
}

\begin{abstract}
In the big data era, the pursuit of the right to be forgotten arises from the data subject's desire to request the removal of his/her personal data. Although the right to be forgotten is hotly debated at the global level, there is a paucity of research into the legislative process of this right. This study aims to scrutinize how legislation on the right to be forgotten evolves in different countries. First, the origin and development of the right to be forgotten are expounded by analyzing the legislation on and the major legislative interpretation of the right. Second, the elements of this right are determined and examined by dissecting the right. Last but not least, the nature of this right is probed into and illustrated. It is found that the soundness of a legal framework for data protection varies from country to country, which indicates that the institutional basis for the right to be forgotten differs markedly. Thereby, countries shall decide whether to legislate to protect the right to be forgotten based on their practicalities. Moreover, according to Article 17 of the General Data Protection Regulation (GDPR), the right to be forgotten is composed of the subject of right (data subject), the subject of obligation (data controller), the object of right (personal data), and the content of right (all links to the personal data, etc., must be deleted by the subject of obligation at the request of the subject of right). Furthermore, there are three typical views about the nature of this right based on scholars' divergent opinions on the relationship among the right to be forgotten, personality rights, rights in personal information, and the right to privacy. It is concluded that countries that do not enjoy mature legislative conditions should not grant the right to be forgotten legal status, although it has been enshrined in law by partial countries with sound legal systems. In addition, the defects in the right's four elements remain to be remedied before it could be legally acknowledged. Finally, the right to be forgotten, in terms of its nature, should be classified as rights in personal information, which are part of personality rights.
\end{abstract}

Keywords: the right to be forgotten, legislative process, elements of right, nature of right

\section{Introduction}

With the rapid development of digital technology and the Internet, human beings have entered the big data era. All information will be perfectly preserved instead of vanishing as in the past.

\footnotetext{
* Acknowledgements: This research is supported by "The Fundamental Research Funds for the Central Universities", Zhongnan University of Economics and Law (Grant Number 2722019JCT018).

XIAO Peng, Ph.D., Lecturer, School of Foreign Studies, Zhongnan University of Economics and Law, Wuhan, China. xiaopeng@zuel.edu.cn.

LIN Haoran, Corresponding author, Research Fellow, Law School, Sun Yat-Sen University, Guangzhou, China. Lumos1995@163.com.
} 
This is reminiscent of the concept of panopticon, put forward by the British philosopher Jeremy Bentham in 1785 . The panopticon allows all inmates to be observed by a single watchman in the inspection house at the center without the inmates being able to tell whether or not and when they are being watched. In this way, the prisoners will be compelled to regulate their own behavior because they would feel like being monitored at all times. As commented by Michel Foucault (1977, p. 201), the panopticon's major effect is "to induce in the inmate a state of conscious and permanent visibility that assures the automatic functioning of power". In the end, the panopticon achieves an effect of self-imprisonment. Will people be imprisoned if information can no longer be forgotten?

Driven by the abovementioned concerns, more and more people contend that we should have the right to (make our information) be forgotten, thereby giving rise to the legalization of the right to be forgotten aimed at protecting the rights of data subjects. One case in point is the EU General Data Protection Regulation (GDPR) that came into effect on May 25, 2018 after a two-year transitional period. Relevant pros and cons debate over the legalization of the right to be forgotten becomes quite intense. ${ }^{1}$

Various issues will be scrutinized to determine whether the right to be forgotten should be legalized, namely, its origin and development, elements as well as nature.

\section{The Origin, Development, and Main Legislative Interpretations of the Right to Be Forgotten}

Both the concept and legislation of the right to be forgotten originated in Europe. As early as in the 1970s, France had granted convicted criminals the right to be forgotten so that they could object to the disclosure of their crimes and sentences after they were released (Rosen, 2012, p. 88). With the development of Internet technologies, EU countries realized the importance of data protection and promulgated data protection laws successively, many of which are related to the right to be forgotten, for example, Article 26 of German Federal Data Protection Act of 1977, Article 36 (right to erasure, right to rectification) of Law 78-17 of January 6, 1978 on Information Technologies, Data Files and Civil Liberties in France, Article 24 (right to rectification and erasure) of Data Protection Act 1984 in the UK and Article 33 (right to erasure) of Dutch Data Protection Act 1989. All these provisions constitute the institutional basis for the right to be forgotten. In 1995, the European Union adopted The Data Protection Directive, short for the Directive 95/46/EC on the protection of individuals with regard to the processing of personal data and on the free movement of such data, where Article 6 (principles of restriction on purposes), Article 12(b) (the right of erasure or blocking data), and so on have reflected the right to be forgotten. In 2010, Viviane Redding, the EU's Commissioner for Justice, Fundamental Rights and Citizenship, presented the European Parliament with a bill on the right to be forgotten. In 2012, the European Commission proposed a regulation of the European Parliament and of the Council on the protection of individuals with regard to the processing of personal data and on the free movement of such data (General Data Protection Regulation), which encompasses the right to be forgotten. ${ }^{2}$ In April 2016, the European

\footnotetext{
${ }^{1}$ A detailed analysis of the pros and cons debate over the legalization of the right to be forgotten could be found in this article. See Xiao, P., \& Lin, H. R. (2019). The right to be forgotten debate: Pros and cons. American Journal of Business, Economics and Management, 7(1), 40-43.

${ }^{2}$ Proposal for a Regulation of the European Parliament and of the Council on the Protection of Individuals With Regard to the Processing of Personal Data and on the Free Movement of Such Data (General Data Protection Regulation) \{SEC (2012) 72 final $\}$ \{SEC (2012) 73 final \}. Brussels, 25.1.2012, COM (2012) 11 final.
} 
Parliament and the Council of the European Union adopted Regulation (EU) 2016/679, ${ }^{3}$ known as General Data Protection Regulation (GDPR). After a transitional period of two years, GDPR came into effect on May 25, 2018.

According to Article 17 of GDPR on Right to erasure (right to be forgotten), the right to erasure means the data subject shall have the right to obtain from the controller the erasure of personal data concerning him or her. This article also stipulates in what circumstances this right applies and its restrictions. The data subject may require the controller to delete his/her personal data under six circumstances: (1) The personal data are no longer necessary in relation to the purposes for which they were collected or otherwise processed; (2) the data subject withdraws consent on which the processing is based according to point (a) of Article 6(1), or point (a) of Article 9(2), and where there is no other legal ground for the processing; (3) the data subject objects to the processing pursuant to Article 21(1) and there are no overriding legitimate grounds for the processing, or the data subject objects to the processing pursuant to Article 21(2); (4) the personal data have been unlawfully processed; (5) the personal data have to be erased for compliance with a legal obligation in Union or Member State law to which the controller is subject; (6) the personal data have been collected in relation to the offer of information society services referred to in Article 8(1). (Hereinafter abbreviated as "unnecessary for the purpose", "withdrawal with consent", "right to object", "unlawfully processed", "legal obligation", and "data of a child".)

The five restrictions of the data subject are equivalent to the five exemptions of the data controller: (1) for exercising the right of freedom of expression and information; (2) for compliance with a legal obligation which requires processing by Union or Member State law to which the controller is subject or for the performance of a task carried out in the public interest or in the exercise of official authority vested in the controller; (3) for reasons of public interest in the area of public health; (4) for archiving purposes in the public interest, scientific or historical research purposes, or statistical purposes, so far as the right to delete is likely to render impossible or seriously impair the achievement of the objectives of that processing; (5) for the establishment, exercise, or defense of legal claims (especially for evidence purposes). (Respectively referred to as: "freedom of expression", "official authority", "public health", "scientific research", and "legal request".)

In addition, other countries also made similar provisions for the right to be forgotten. South Korea amended the Act on Promotion of Information and Communications Network Utilization and Data Protection in 2012 and confirmed data subject's right to be forgotten. The law stipulates that if a user does not use information and communication services for a certain period of time, the provider of information and communications services shall destroy the user's personal information (Peng, 2014, p. 37). In February 2012, the US government announced the Consumer Privacy Bill of Rights, which set seven principles to protect users' privacy, including individual control (consumers have a right to exercise control over what personal data companies collect from them and how they use it), respect for context (consumers have a right to expect that companies will collect, use, and disclose personal data in ways that are consistent with the context in which consumers provide the data), accountability (consumers have a right to have personal data handled by companies with appropriate measures in place to assure they adhere to the Consumer Privacy Bill of Rights), etc. This Act gives network users the right to delete their personal information, thereby limiting the use of it

\footnotetext{
${ }^{3}$ Regulation (EU) 2016/679 of the European Parliament and of the Council of 27 April 2016 on the protection of natural persons with regard to the processing of personal data and on the free movement of such data, and repealing Directive 95/46/EC (General Data Protection Regulation), OJ: JOL_2016_119_R_0001.
} 
(Gao, 2016, p. 24). In March 2012, the Final Recommendation Report on Protecting Consumer Privacy issued by the US Federal Trade Commission categorically invoked the European proposal: The right to be forgotten was established within the framework of the Federal Trade Commission, and the data subject has the right of access to the data collected about them and deleting or restricting the use of their data under certain circumstances. ${ }^{4}$ In 2013, California Governor Jerry Brown signed the California SB 568 into law, ${ }^{5}$ known as the Eraser Law, which came into effect on January 1, 2015. The Eraser Law requires social networking giants, including Facebook and Twitter, to allow minors to erase their online tracks to avoid the lingering network traces in the future due to lack of awareness of cybersecurity (Yang \& Han, 2015, p. 24). On July 13, 2015, the Russian President signed Federal Law No. 264-FZ, amending the Federal Law No. 149-FZ on Information, Information Technologies, and Information Protection, and Articles 29 and 402 of the Civil Procedural Code of the Russian Federation (also known as the "right to be forgotten" Law), which stipulates the obligations of the search system manager, the content of the applicant's request, the processing system manager's processing procedures, and other content related to the right to be forgotten (Zhang, 2016, pp. 102-103).

The provisions similar to those on the right to be forgotten in Chinese laws are mainly scattered in decisions and laws such as Article 8 of Decision of the Standing Committee of the National People's Congress on Strengthening Information Protection on Networks, Article 36 of the Tort Liability Law, Article 43 of the Cyber Security Law, Article 111 of General Provisions of the Civil Law and in guidelines such as "Information Security Technology — Guidelines for the Protection of Personal Information in Public and Commercial Service Information Systems". According to Information Security Technology-Guidelines for the Protection of Personal Information in Public and Commercial Service Information Systems, the processing of personal information in information systems may be divided into four major steps, namely, collection, processing, transfer, and deletion. The protection of personal information runs through the four steps. Article 8 of Decision of the Standing Committee of the National People's Congress on Strengthening Information Protection on Networks also states:

citizens who discover any network information divulging their personal identities, disseminating their individual privacy or otherwise infringing upon their lawful rights and interests or who are annoyed by unwanted commercial electronic information shall have the right to require network service providers to delete relevant information or take other necessary prohibitive measures.

Nonetheless, the right to be forgotten has yet to be stipulated clearly in the abovementioned decisions, laws, and guidelines in China, despite limited guidance on personal information protection and tort liability.

Having examined the legislative development of the right to be forgotten in different countries, the following section would focus on its four elements.

\section{Deconstruction and Analysis of the Right to Be Forgotten}

Generally speaking, a legal right consists of the subject of right, the subject of obligation, the object of right, and the content of right. For the right to be forgotten, the subject of right is the subject who enjoys and exercises the right to be forgotten according to the law; the subject of obligation is the subject who responds to the request of the subject of right and fulfill his/her obligations according to the law; the object of right refers to

\footnotetext{
${ }^{4}$ Federal Trade Commission (2012), Federal Trade Commission Report: Protecting Consumer Privacy in an Era of Rapid Change: Recommendations for Businesses and Policymakers.

52013 Cal. Legis. Serv. Ch. 336 (S.B. 568).
} 
the object to which the rights and obligations are directed; the content of right denotes the specific way in which the right is exercised and its ensuing effects. It's believed that it is necessary to deconstruct the right to be forgotten according to Article 17 and Article 4 of GDPR before the advantages and disadvantages of this right are discussed in depth.

First, according to Paragraph 1 of Article 17, "the data subject shall have the right to obtain from the controller the erasure of personal data concerning him or her without undue delay". According to the Paragraph 1 of Article 4, the "data subject" is:

an identifiable natural person is one who can be identified, directly or indirectly, in particular by reference to an identifier such as a name, an identification number, location data, an online identifier or to one or more factors specific to the physical, physiological, genetic, mental, economic, cultural or social identity of that natural person.

It can be inferred that the subject of the right to be forgotten is the "data subject", namely the natural person who generates personal data and can be identified by direct or indirect means. In the big data era, therefore, a mass of people needs to exercise the right to be forgotten, giving rise to a deluge of the subjects of right.

Second, according to Paragraph 1 of Article 4, "data controllers" refer to "the natural or legal person, public authority, agency or other body which, alone or jointly with others, determines the purposes and means of the processing of personal data". Hence, the subject of the right to be forgotten is the data controller who responds to the data subject's request, namely those who control personal data with the consent of data subjects or on other legitimate grounds. In the Internet age, various search engine companies and social networking sites (such as Google, Yahoo, and Baidu) are often the major subjects which collect personal data, with whom natural persons often have disputes over the right to be forgotten in reality. Nevertheless, information technology enterprises, as the subjects of this right, will hardly be capable of addressing a sea of user information and numerous related demands.

Third, the object of the right to be forgotten is "personal data", that is, any identified or identifiable information related to a natural person ("data subject"). At the same time, Paragraph 1 of Article 17 also classifies personal data applicable to the right to be forgotten into six categories: "unnecessary for the purpose", "withdrawal with consent", "right to object", "unlawfully processed", "legal obligation", and "data of a child". These six types of personal data are the object of right that both the rights and obligations of the right to be forgotten are directed to. It can be observed that the boundary of the object of this right is not clear.

Fourth, according to Paragraph 2 of Article 17:

where the controller has made the personal data public and is obliged pursuant to paragraph 1 to erase the personal data, the controller, taking account of available technology and the cost of implementation, shall take reasonable steps, including technical measures, to inform controllers which are processing the personal data that the data subject has requested the erasure by such controllers of any links to, or copy or replication of, those personal data.

Therefore, the content of the right to be forgotten is that the subject of right (data subject) has the right to request the subject of obligation (data controller) to delete and notify other relevant data controllers to erase any links to, or copy or replication of the abovementioned six kinds of personal data.

The cyberspace is characterized by an enormous number of users, rapid data transmission, and information dissemination through backup copies that is difficult to be controlled.

For data controllers, to erase related links, backups, or duplicates completely is an almost impossible task. It is even more demanding to ask them to identify and notify other relevant data controllers to complete the 
erase job. Even if data controllers can really meet some of the requirements, they will bear a considerable burden. Therefore, the content of the right to be forgotten under Article 17 of GDPR is unrealistic.

In summary, the problems in these four aspects make this right far from being a mature legal right to be introduced into more countries. In this case, the nature of this right needs to be clarified.

\section{The Nature of the Right to Be Forgotten}

No consensus has been reached on which category the right to be forgotten should fall into. The controversy centers on the relationships between the right to be forgotten and personality rights, the right to privacy, which belongs to personality rights, and the right in personal information that has not been legislated for.

First of all, regarding the relationship between the right to privacy and the right in personal information, Wang Liming (2012, p. 120) believes that the right in personal information should not be classified as a right to privacy because it is comparatively independent of the right to privacy. On the contrary, Wang Zejian (2013, pp. 208-209) argues that the right to privacy denotes individuals' rights to exercise autonomy in their private spheres and is composed of private space and information autonomy (the right in personal information). In this way, the right in personal information belongs to the right to privacy.

Second, which kind of right should the right to be forgotten be classified as? Yang Lixin and Han Xu (2015, p. 31) contend that the right to be forgotten should be categorized as "the right in personal information" as part of personality rights, and should be confirmed in the legislation of the future personal information protection law. This view is also held by Liang Chenxi and Dong Tiance (2015, p. 33), Wan Fang (2016, p. 161), Duan Weili (2016, pp. 76-79), Luo Liuhu (2016, p. 36), and so on. Peng Zhiyuan (2014, p. 37) asserts that the right to be forgotten should be regarded as an independent right; Zheng Zhifeng (2015, p. 59) claims that the right to be forgotten should be included in the right in personal information, but the latter is not part of the personality rights. Tao Qian $(2015$, p. 126) holds the opinion that the right to be forgotten is not new, but a mechanism to cope with the threats to privacy protection posed by technological innovations in the digital era. In essence, the right to be forgotten constitutes the right to privacy.

It can be concluded that opinions about the nature of the right to be forgotten are drastically divided among Chinese scholars. A majority of scholars champion the establishment of the right in personal information as a new type of personality rights and advocate that the right to be forgotten should be classified as the right in personal information. Some scholars think that the right to be forgotten is a component of the right to privacy or the right in personal information that is independent of the personality rights.

\section{Conclusion}

Although the right to be forgotten has been legally acknowledged in some countries, it is the author's contention that the right to be forgotten, provided for by Article 17 of the GDPR, should not be legalized. In view of this right's four elements, drawbacks such as an excessive number of subjects of right, the incompetence of subjects of obligation, vague boundaries among the objects of right, and the difficulty in implementing the right render, it is infeasible to establish this right. In light of the nature of the right, the boundaries between the right to be forgotten and personality rights (including the right to privacy and the right in personal information) are too unclear to make it an independent right, therefore the legislation of this right is far from necessary.

Thereby, it is believed that countries that have acknowledged the right to be forgotten, such as the EU 
countries, South Korea, the United States, and Russia, should improve their laws and regulations based on a dynamic balance among the right to be forgotten, freedom of speech, and the right to know. As for countries that have not legalized it, the right to be forgotten should first be incorporated into the right to privacy or the right in personal information, and only be legislated for if suitable conditions are provided.

\section{References}

Duan, W. L. (2016). The legal protection of the right to be forgotten - and this right's status in personality rights. Study \& Exploration, 4, 74-80.

Foucault, M. (1977). Discipline and punish. London: Tavistock.

Gao, J. (2016). Difference and comparison: The right to be forgotten in the European Union law and American law. Sichuan University of Arts and Science Journal, 26(4), 24-30.

Liang, C. X., \& Dong, T. C. (2015). The nature and boundaries of right to be forgotten in a big data era. Academic Research, 9 , 31-36.

Luo, L. H. (2016). The right to be forgotten: Regulating irrelevant personal information in search engines by private law. Journal of Chongqing University of Posts and Telecommunications (Social Science Edition), 28(3), 34-43.

Peng, Z. Y. (2014). On the right to be forgotten. Journal of North University of China (Social Science Edition), 30(1), 36-40.

Rosen, J. (2012). The right to be forgotten. Stanford Law Review Online, 64, 88-92.

Tao, Q. (2015). Right to be forgotten in the digital era - a request of the right of a clean record. Modern Communication, 37(6), $125-130$.

Wan, F. (2016). Right doomed to be forgotten. Law Review, 34(6), 155-162.

Wang, L. M. (2012). Re-definition of right to privacy. The Jurist, 1, 108-120+178.

Wang, Z. J. (2013). Laws of personality rights. Beijing: Peking University Press.

Xiao, P., \& Lin, H. R. (2019). The right to be forgotten debate: Pros and cons. American Journal of Business, Economics and Management, 7(1), 40-43.

Yang, L. X., \& Han, X. (2015). The localization and application of the right to be forgotten in China. Journal of Law Application, 2, 24-34.

Zhang, J. W. (2016). The intent, framework and features of Russian legislation on the right to be forgotten. Seeking Truth, 43(5), $102-110$.

Zheng, Z. F. (2015). A study on right to be forgotten in the internet society. Studies in Law and Business, 32(6), 50-60. 